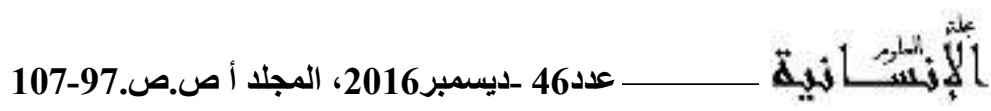

\title{
الجوانب النظرية والتطبيقية للصكوك الإسلامية
}

\author{
أ.محمد باوني \\ كلية الحقوق التق \\ جامعة الإخوة منتوري قسنطينة
}

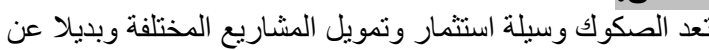

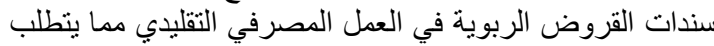

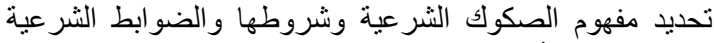

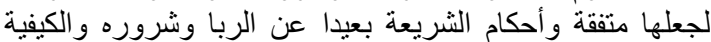

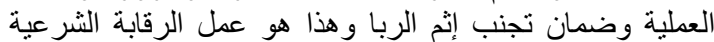

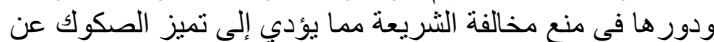

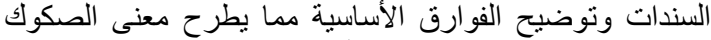

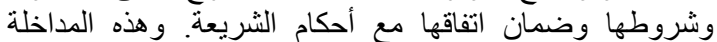

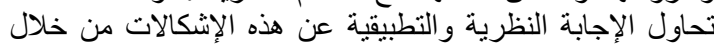

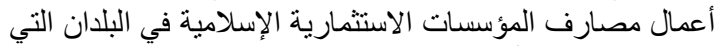

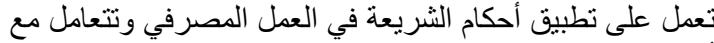

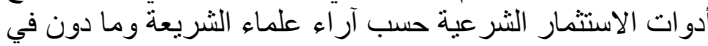

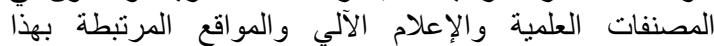

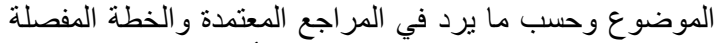

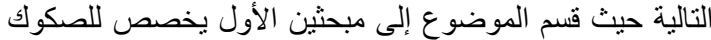

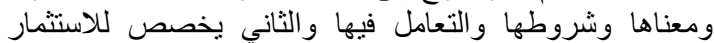

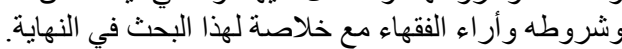

\section{Abstract :}

تعد الصكوك وسيلة استثمار وتمويل

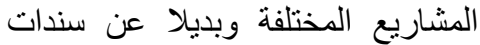
القروض الربوية في العمل المصرفي

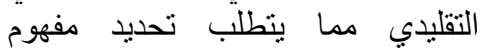

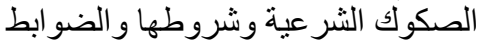

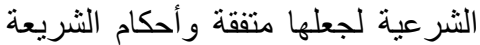
بعيدا عن الربا وشروره و والكيفية العملية

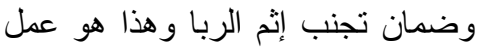
الرقابة الثر عية ودور ها في منع مخالفة ولئة

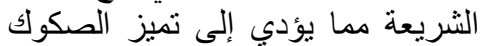
عن السندات وتوضيح الفوارق الأساسية

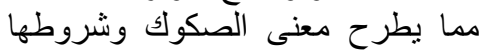
وضمان اتفاقها مع أحكام الثريعة ورئه المداخلة تحاول الإجابة التابة النظرية

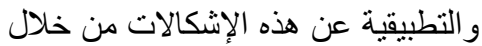

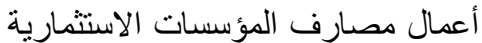
الإسلامية في البلدان التي تعمل على التى تطبيق أحكام الثريعة.
Instruments are a means of investment and financing various projects and a substitute for usurious loan bonds in conventional banking. This requires defining the concept, conditions and legal controls of instruments compatible with Sharia, away from the evils and sins of usury. This is the job and role of Sharia Supervisory, to prevent violation of Sharia; it distinguishes the basic differences between instruments and bonds, thus clarifies the meaning and conditions of instruments and what is found in approved references . 
المبحث الأول: تعريف التصكيك:

هنالك ارتباط كبير بين التصكيك والاستثمار باعتبار أن التصكيك و هو إصدار الصكوك الصارئ الصالية بقيم معينة

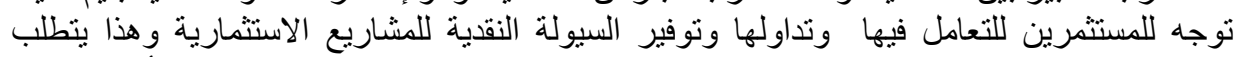

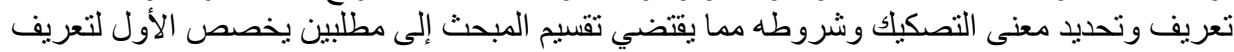

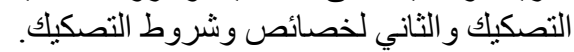

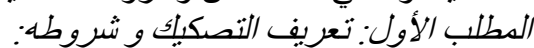

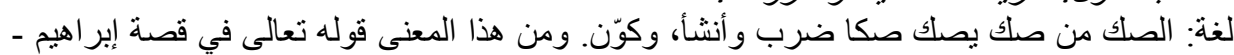

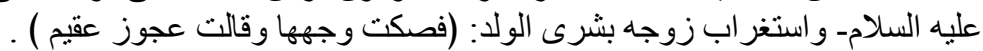

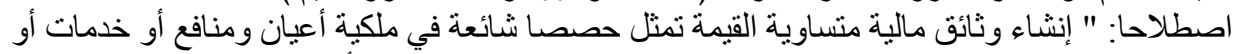

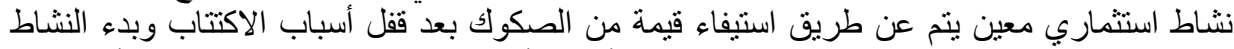

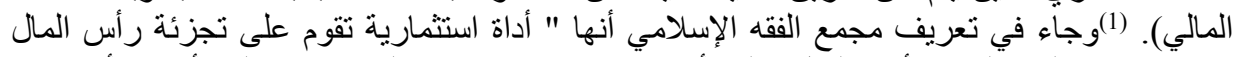
بإصدار صكوك بملكية رأس المال على أساس وحدات منساوية القيأ القيمة ومسجلة بأسماء أصحابها

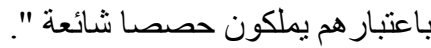
فالصكوك عبارة عن أوراق مالية تصدر عن مؤسسات مالية شرعية تلتزم بأحكام الثريعة حيث تقوم

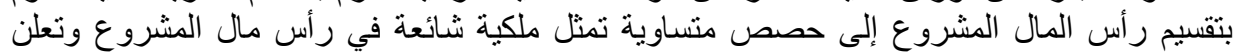

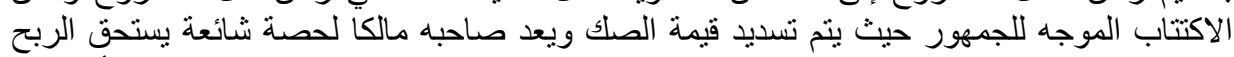

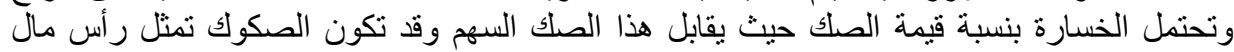

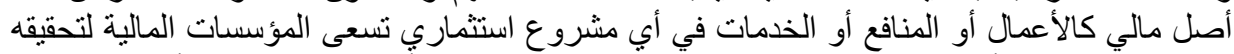

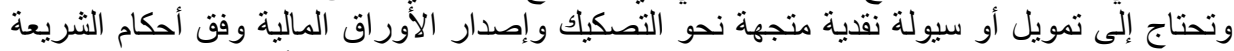

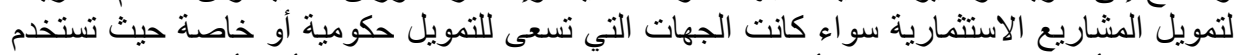

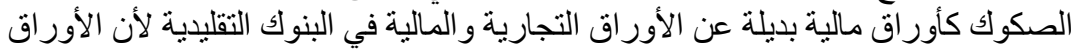

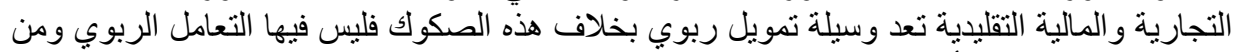

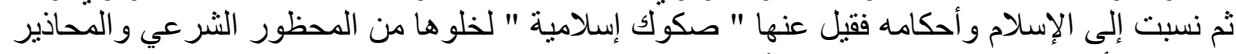
المخالفة لأحكام الثريعة الإسلامية وآراء الفقهاء في التعامل الربوي والمهاء والمحرمات المخألفة لـقاصد

$$
\text { الثربعة. }
$$

المطلب الثاني: شروط وخصائص الصكوك:

وللصكوك الإسلامية عدة مز ايا وشروط شر عية يجب تو فر ها في التعامل الاستثماري و المالي و هي:

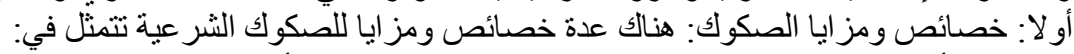

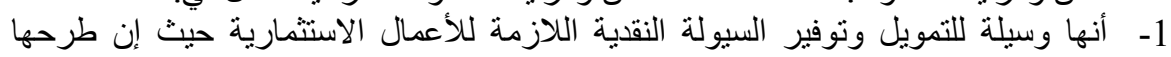

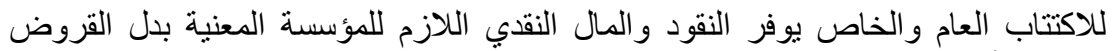

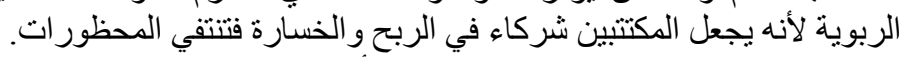

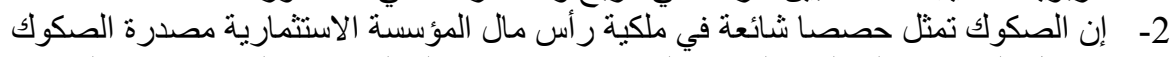

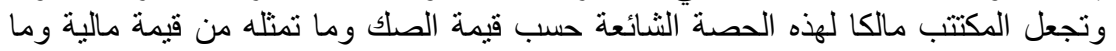

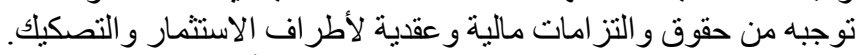

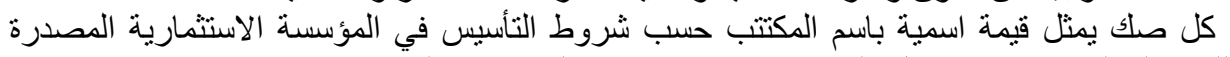

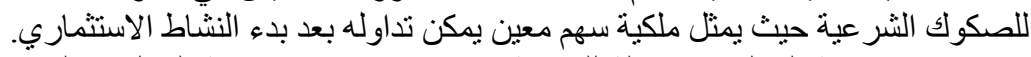

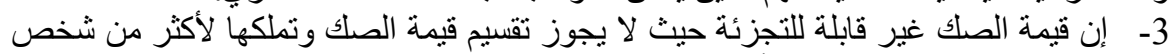

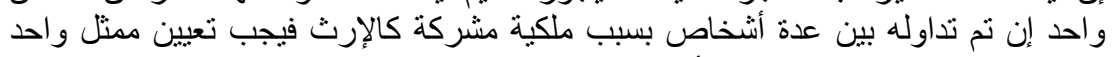
لهؤلاء المالكين للحصة الثائعة أمام المؤسسة المصدرة للصكوك كع مع احتفاظهم بحقوقهم

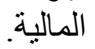

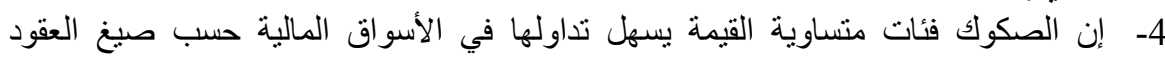
الثر عية وهي المضاربة و المشاركة و المر ابحة و غير ها في من عقود تستعمل في الاستثمار. 


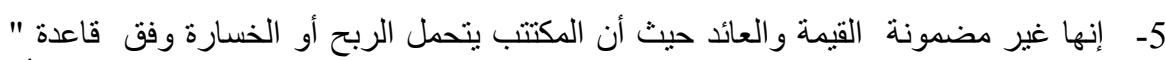

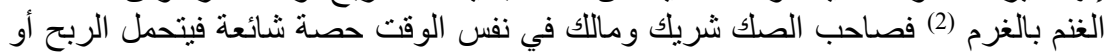

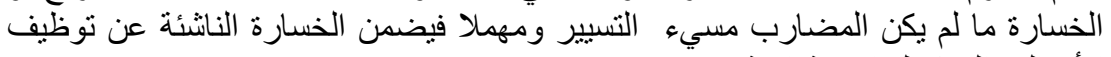
الأمو ال و الصكوك لمك الاستثمارية.

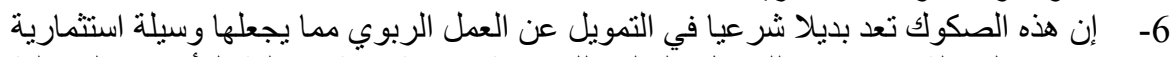

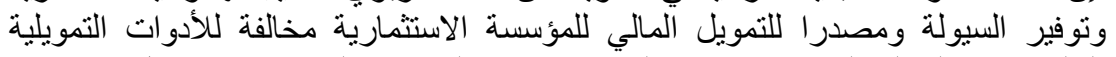

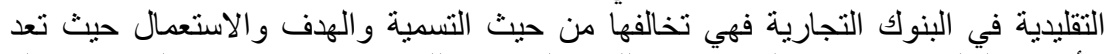

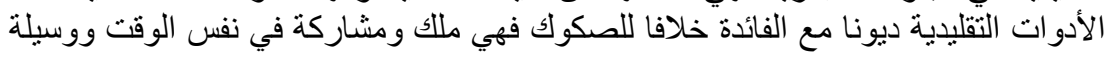
استثمارية. ثانيا : شروط الصكوك الثر عية : وباعتبار الصكوك أداة تمويل فيشترط فيها ما يلي:

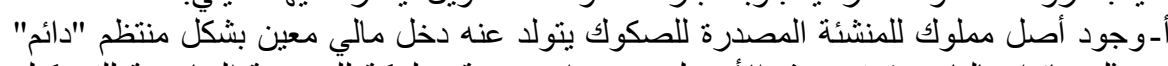

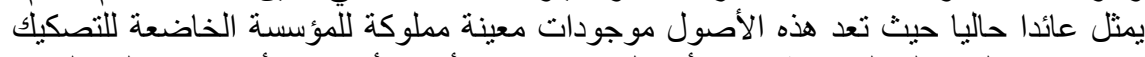

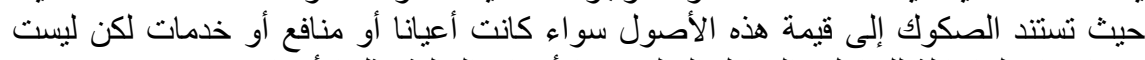

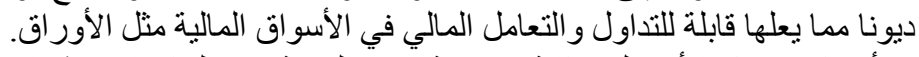

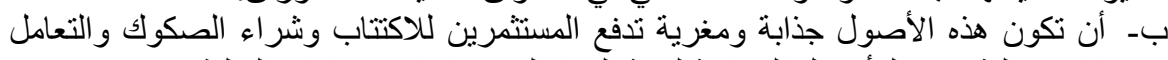

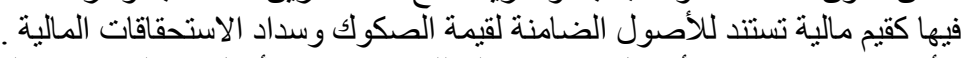

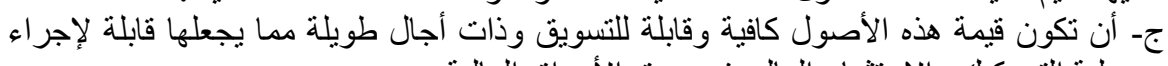

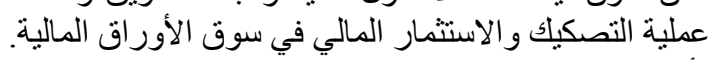

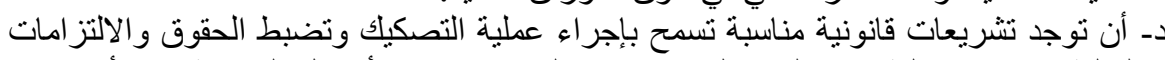

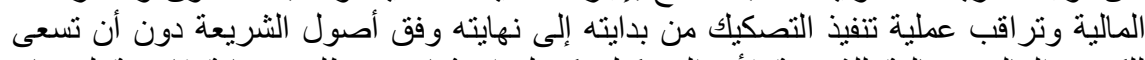

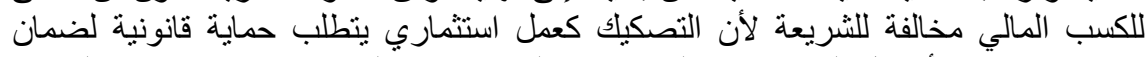

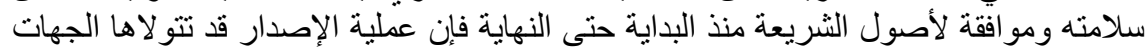

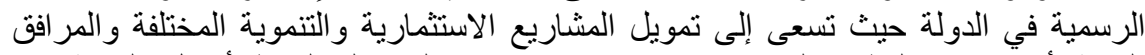

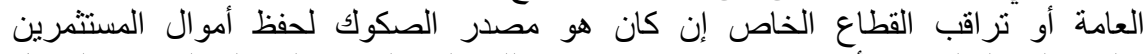

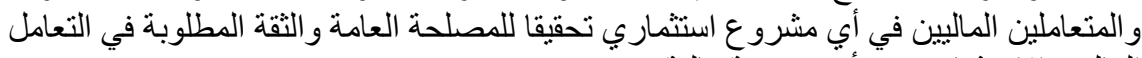

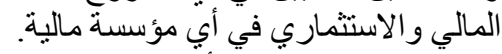

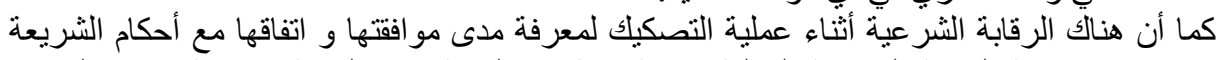

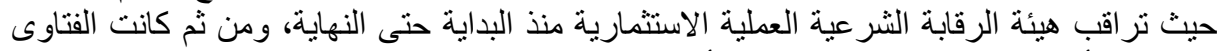

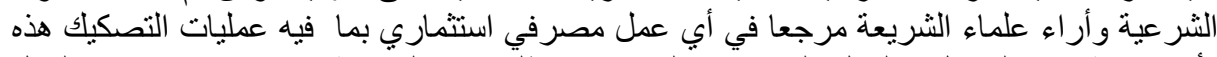

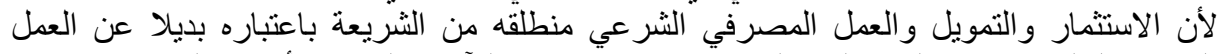

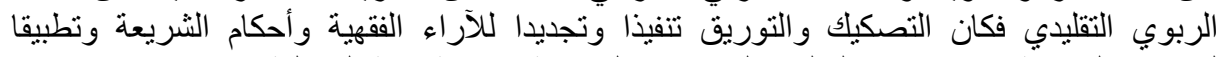
لمقتضى الثريعة الاقتصادي والمالي و المعاملات الثر عية و الاستثمارية المختلفة.

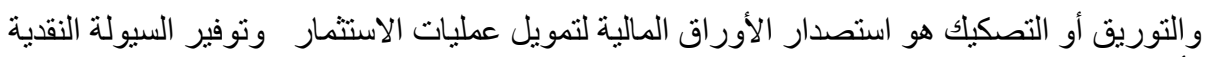

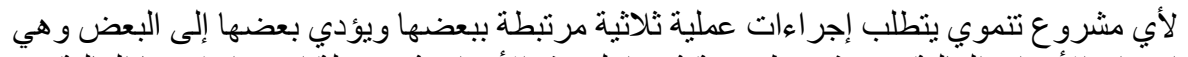

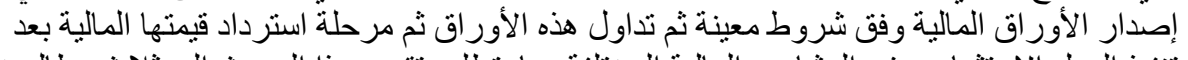

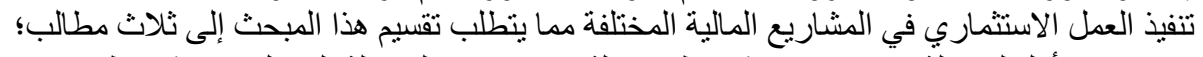

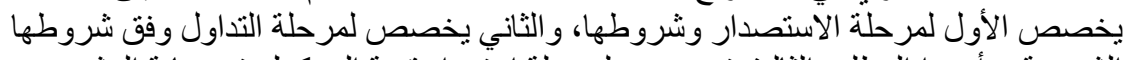
الثر عية، وأخيرا المطلب الثالث فيخصص لمرحلة استرداد قيمة الصكولك في نهاية المشروع: 


$$
\text { المطلب الأول: مرحلة الاستصد/ر: }
$$

و هذه المرحلة تعد الخطوة الأولى نحو إصدار الصكوك الصن حيث تتم بعد التفكير في عمل التمويل، وتقدير

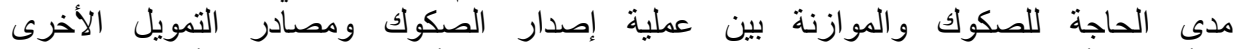

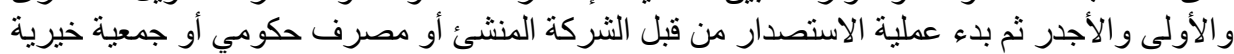

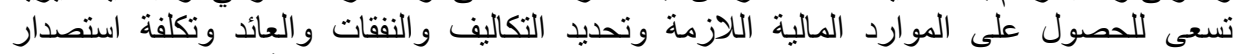

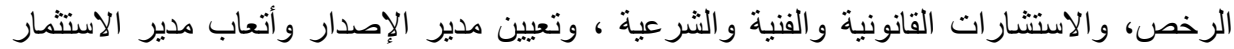

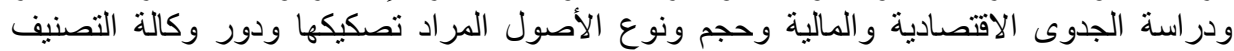

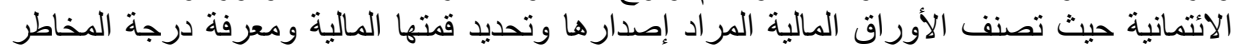

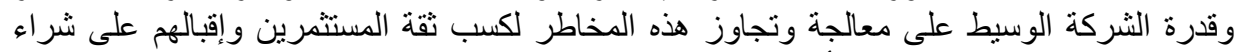

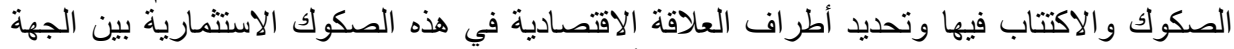

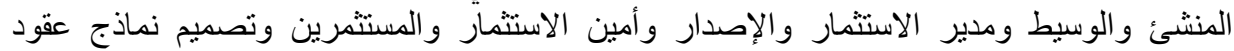

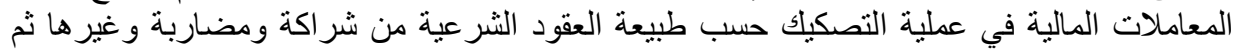

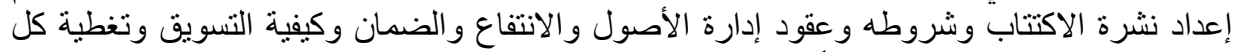

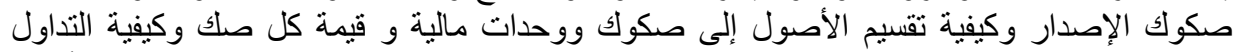

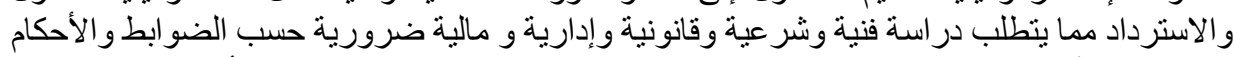

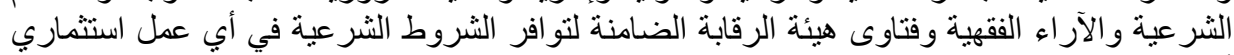

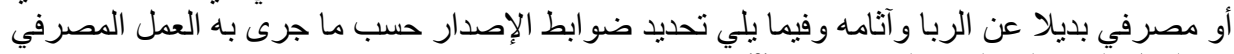

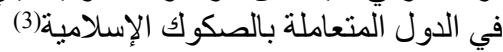

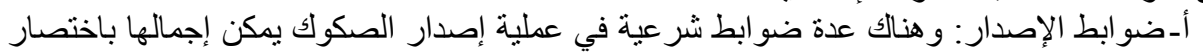
في النقاط التالية: - الإندا:

1- أن يتم إصدار الصكوك وفق أحكام المعاملات الثرعية حيث يترتب الأثر بمجرد التعاقد

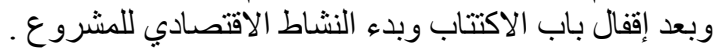

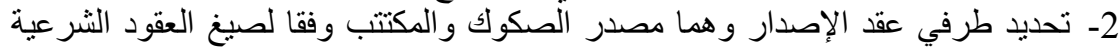

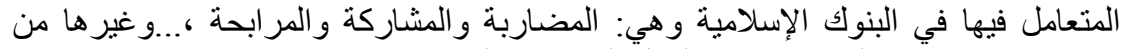

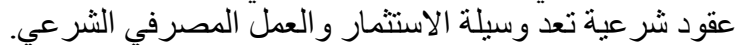

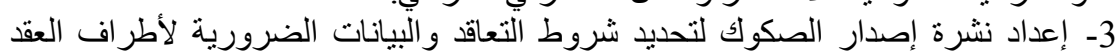

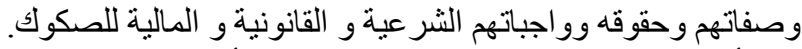

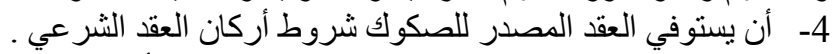

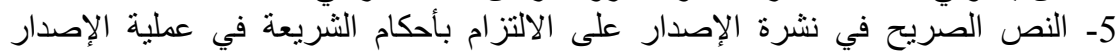

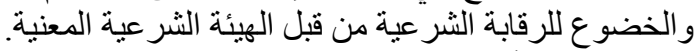

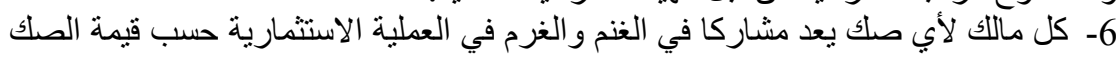

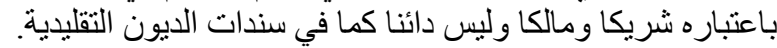

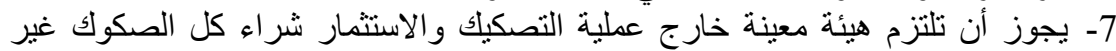

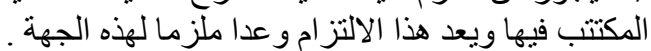

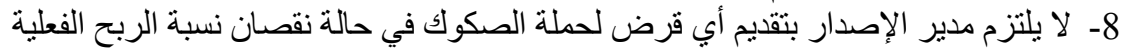

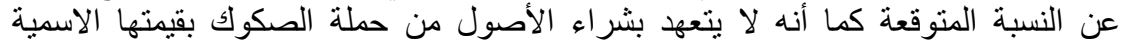

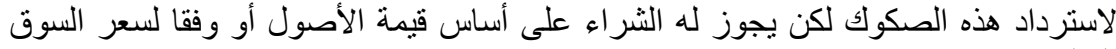

9- إن مدير الصكوك في حالة سوء إدارته أو إهماله ملزم بضمان رأس المال حسب القيمة الاسمية للأصول مدير الصكولك. 
10- إن مجلس الفتوى الثرعي الماليزي أصدر فتوى تتعلق بتحديد بيع سعر الأصول

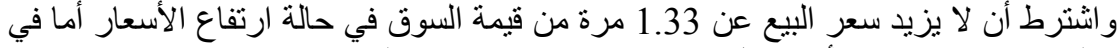

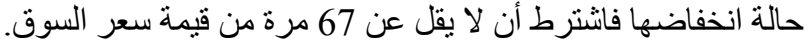
المطلب الثاني: مرحلة التنداول (4).

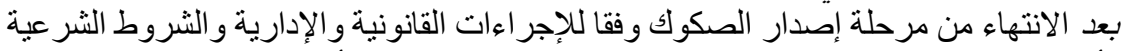

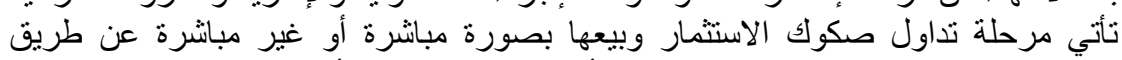

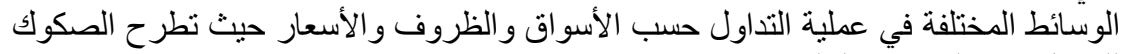

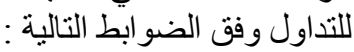

1- أن تكون الصكوك مملوكة ملكية تامة لحاملها وفق أصول حقيقية موجودة كالأعيان

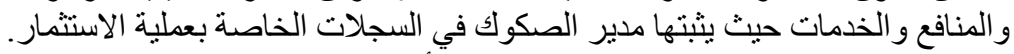

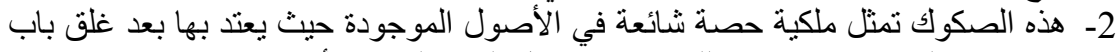

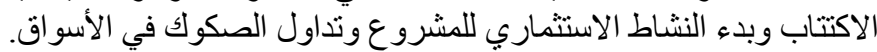

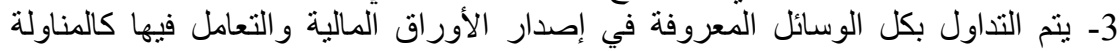
اليدوية و القيد في السجلات والإشهار والإعلاّلام الآلي. 4- يجوز تداول صكوك الأصول المؤجرة بعد إصدار هذه الصكوك كل بعد تملك الحملة للأصول

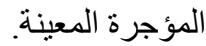
5- يجوز تداول صكوك ملكية المنافع قبل إجارة الأعيان فإن أعيدت الإجارة أعتبر الصكك

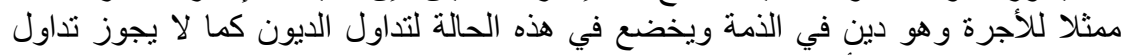

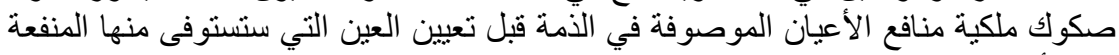

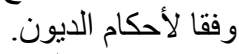

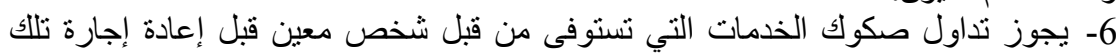

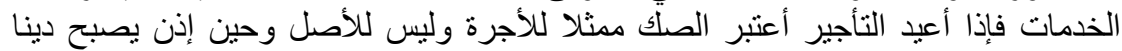

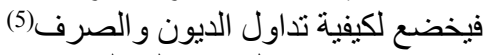

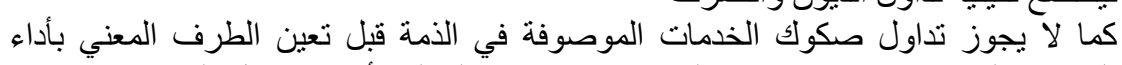

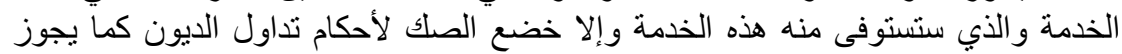

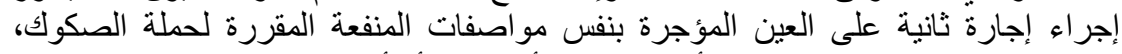
ويجوز للمشترك الثاني في منافع الأعيان المعينة أن يبيعها أو أن يصدر بها الفية صكوكا استثمارية

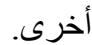

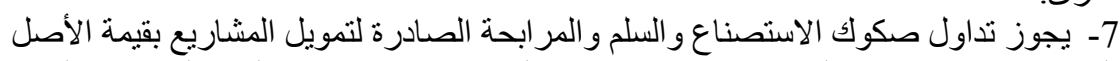

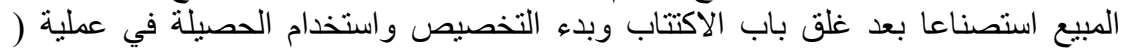

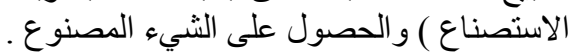

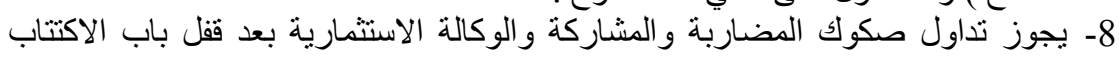
وتحديد قيمة الصكوك وبد وبد النشاط الاستثماري.

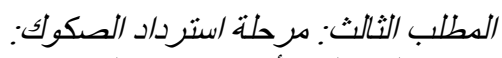

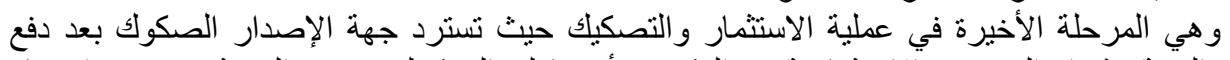

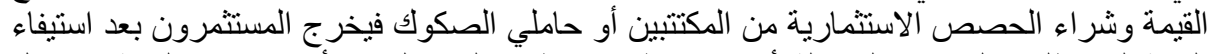

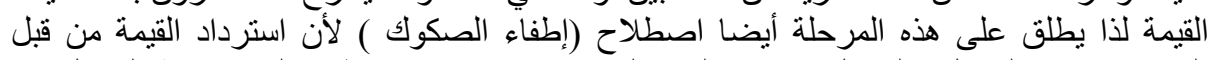

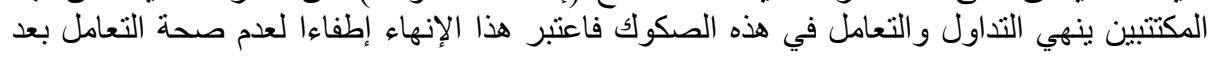

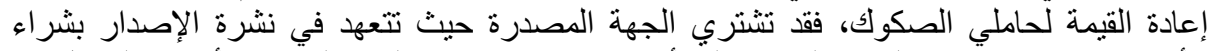

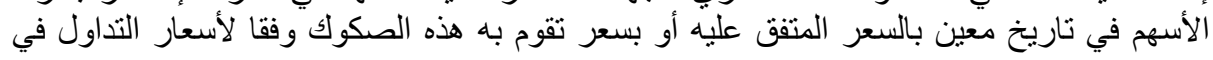


السوق المالية وقد يكون التعهد بالثر اء صادر المن مؤسسة أخرى تتولى تسديد القيمة فيكون التعهد في

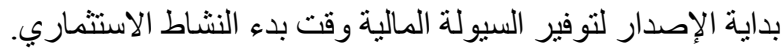

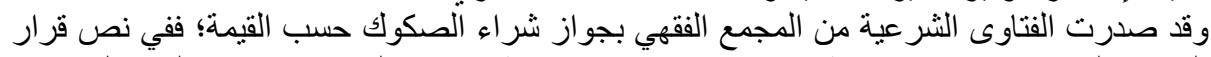

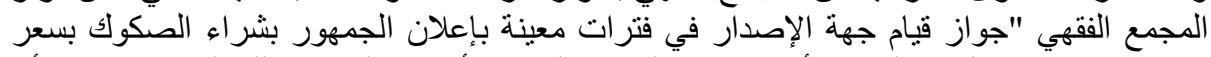

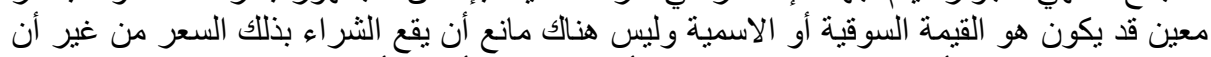

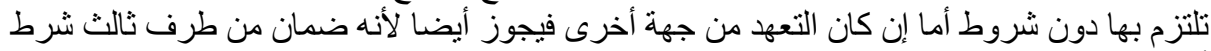
أن لا يكون هذا الطرف مملوكا وتابعا لجهة الإصدار وبها وبما لا يزيد سعر شر اء الصكو لك عن 36 \%من

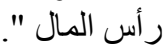

و هذا الاسترداد أو الإطفاء يتم بطريقتين إحداهما: أن يكون بالتتضيض و هو تحويل السلع و الأصول

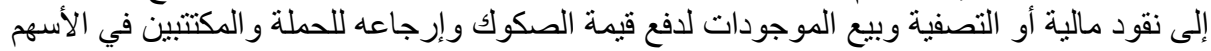

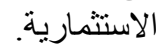

وقد يكون الاسترداد عن طريق التقويم الدوري حيث تدفع قيمة الصكوك بشكل دوري وخلال فترات

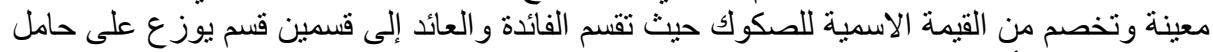

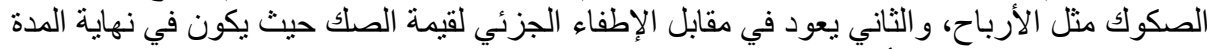

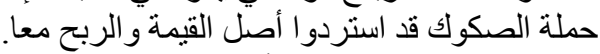

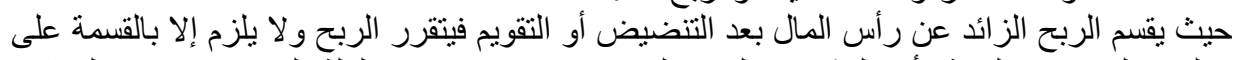

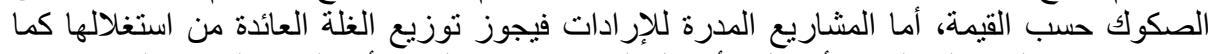

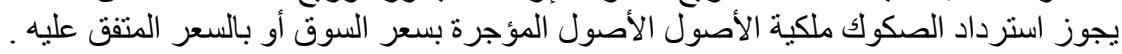

المبحث الثالث: مغنى الاستثمار و أساليبه:

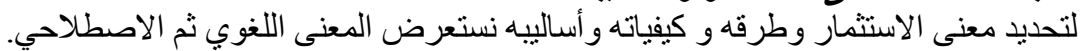

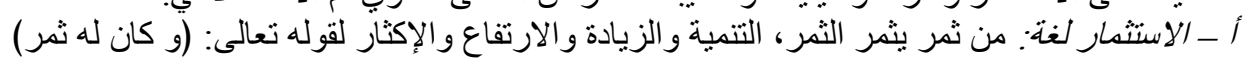

'ب - اصطلاحا: توجد عدة تعاريف يقصد بها توظيف المال وزيادته عن طريق الاستعمال والتنمية

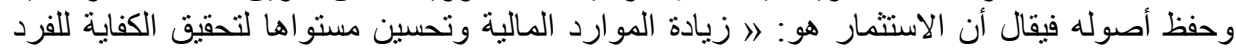

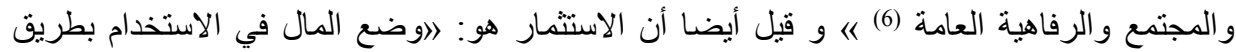

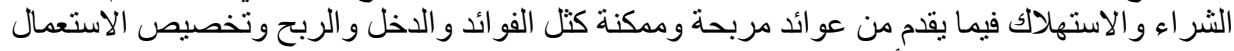

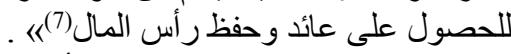

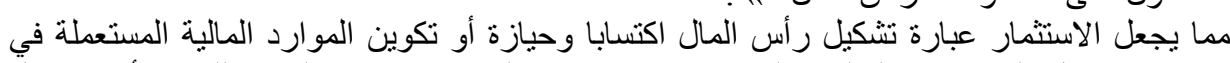

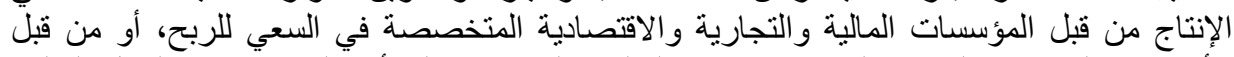

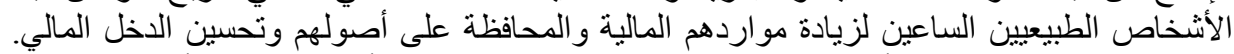

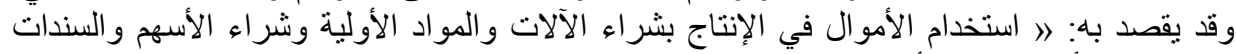

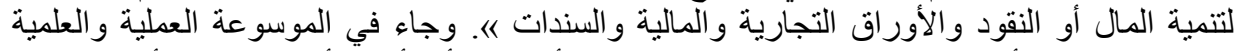

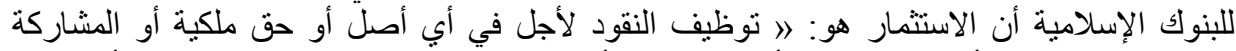

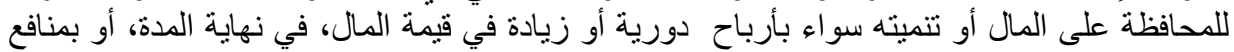
غير مالية (8) به. ومن خلال هذه التعاريف المتكاملة والتي تدور حول رأس المال و الفو ائد و التوظيف و الربح فان عملية

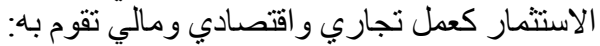
1 - مؤسسات مالية وتجارية متخصصةٌ مثل المصارف التهارية التجارية و الثركات التجارية و المالية ورجال 
2 - تجميع رأس المال من خلال الودائع أو القروض أو العمل المصرفي وفتح الحسابات المصرفية وعمليات الادخار ثم تعيد توظيف هذه الأموال إما بالقروض المبال المباشرة أو غير المبانشرة وربح فارق المبرف

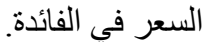

3 - إنشاء المشاريع الاستثارية كالزراعة والصناعة والبضائع و السلع والاستير اد و التوريد وتربية المو انشي و اللحوم وشر اء العقار ات والمباني.

4 - المشاركة في إنشاء المشاريع وتمويلها بعد الدراسة وتقيبم المشروع و الربحية و الدصاريف و النفقات

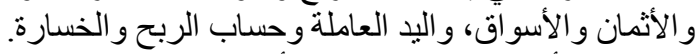

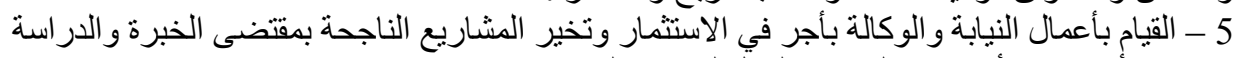

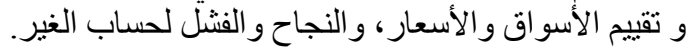

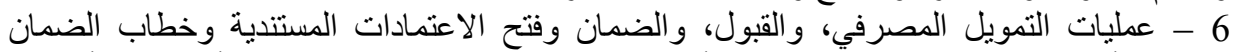

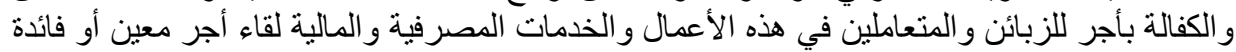
و أجر في نفس الوقت لزيادة المداخيل و الموارد المالية.

7 - المحافظة على رأس المال سالما دون نقصان أو خسارة وهي أدنى عمليات التجارة وحفظ المال

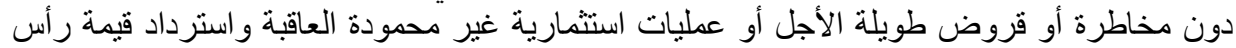

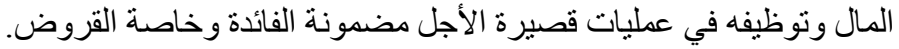

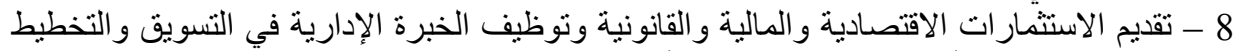
وتتفيذ عمليات تجارية أو تخليص السلع مقابل أجر معين لزيادة الموارد المالية المارية وتوسيع المداخيل دون

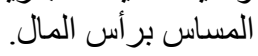
9 - تقديم الخدمات المصرفية وتأجيرها لتوسيع العمل التجاري والمالي، وتكامل الأعمال وتحقيق

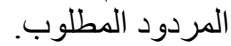

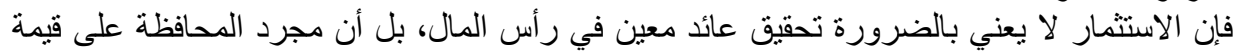

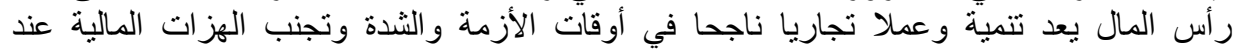

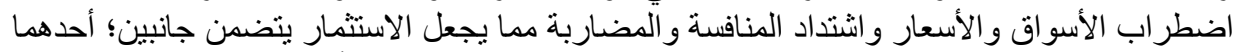

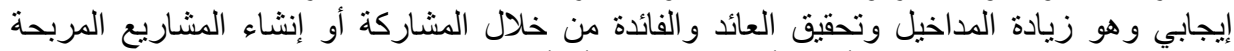

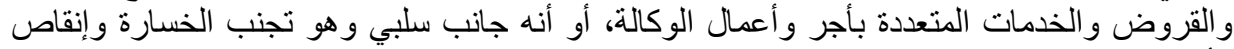

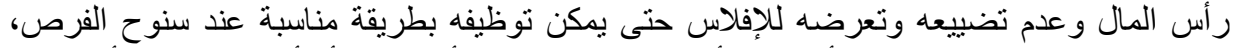

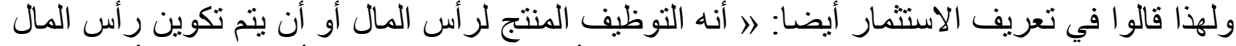

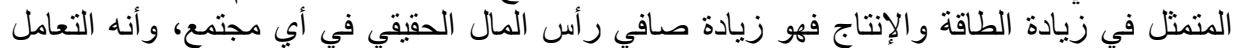

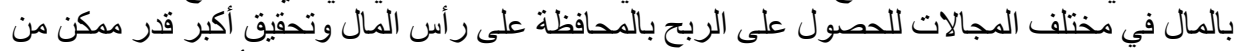

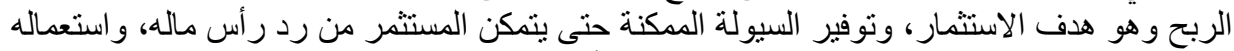

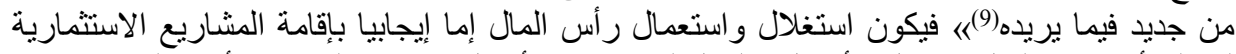

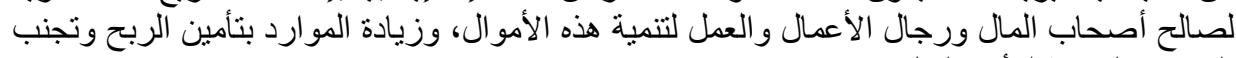

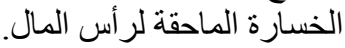

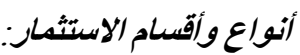
غاية الاستثمار المالي والتجاري: هي الرفاهية الاقتصادية ولهذا يمكن تقسيم الاستثمار إلى نوعين الثين

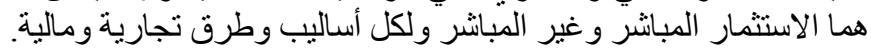

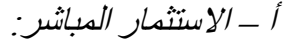


و هو توظيف المال بصفة مباثرة في المشاريع التجارية وتكوين رأس مال جديد وتوسيع النشاط و الطاقة

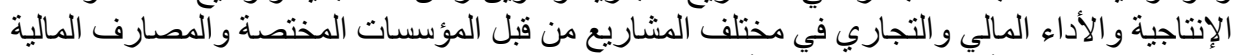

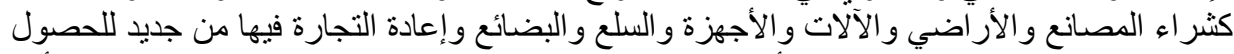

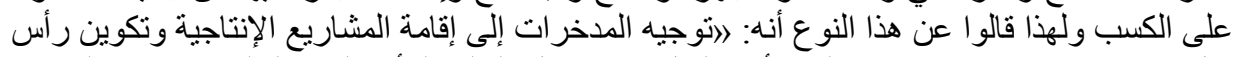

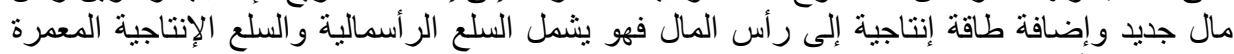

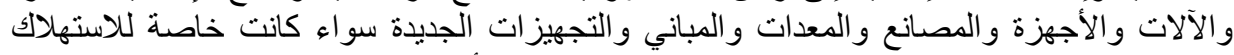

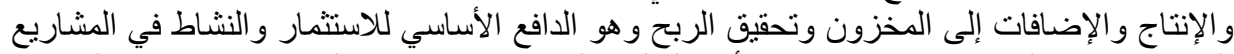

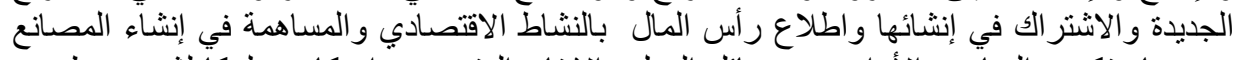

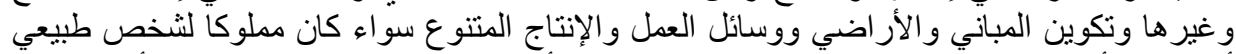

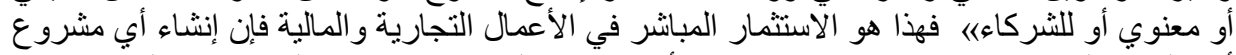

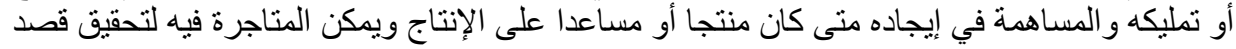
توظيف المال والربح وضمان العائد فإن هذا كله يعد عملا استثماريا.

ب - ب الاستثمار غبر المباشر:

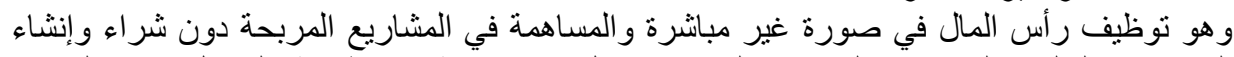

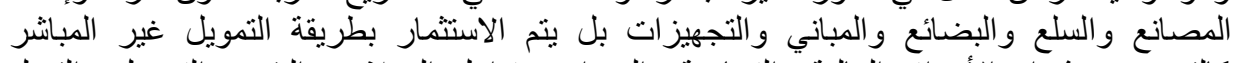

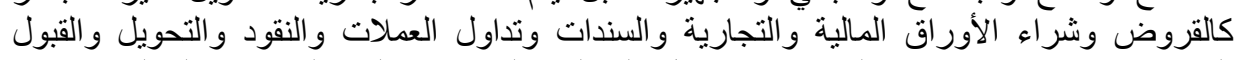

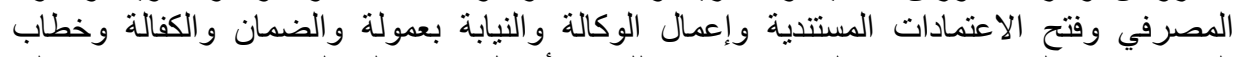

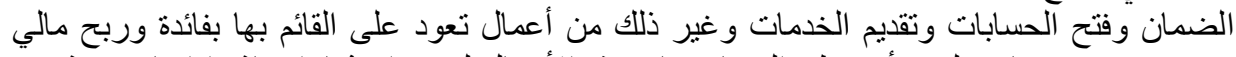

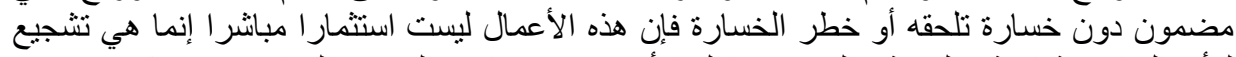

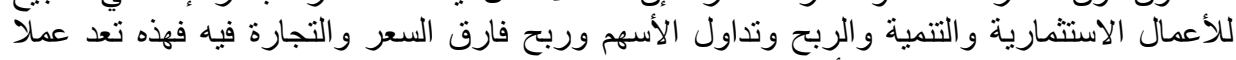

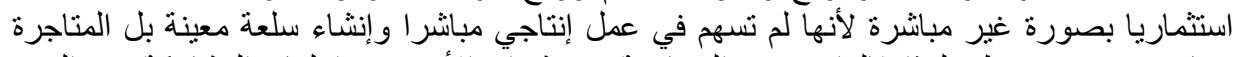

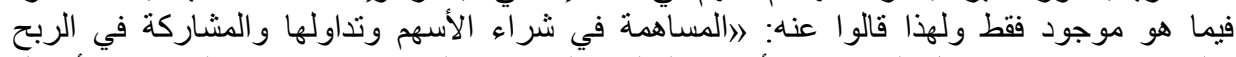

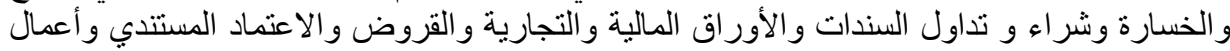

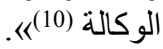

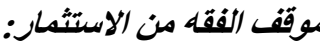

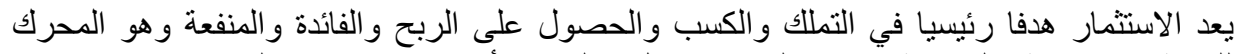

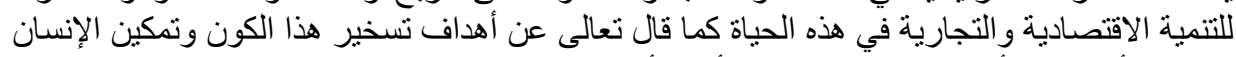

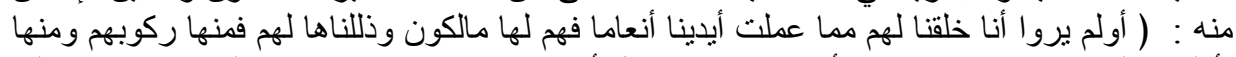

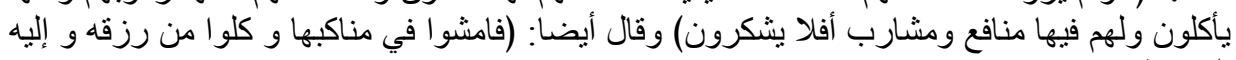

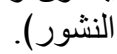

يعد الاستثمار من الأعمال المشروعة والجائزة في الأموال والعقود المالية والتجارية والأملاك لأن ألنان

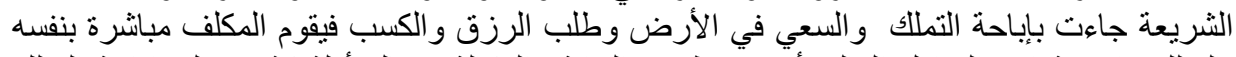

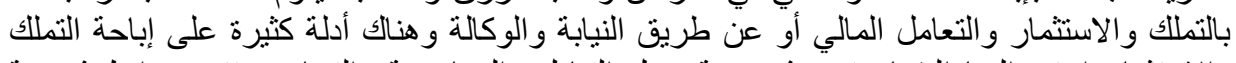

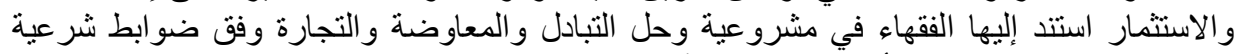

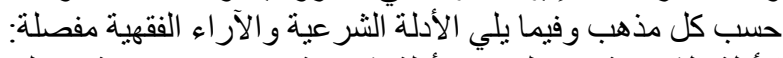

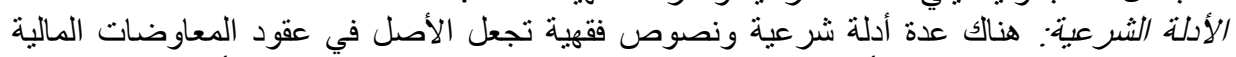

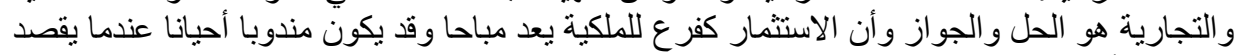

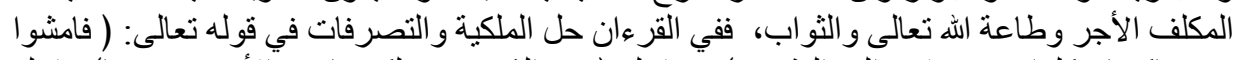

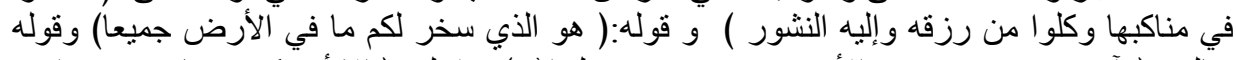

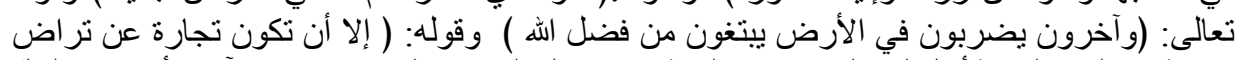

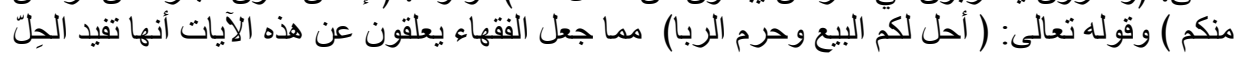


و الإباحة حسب الدذاهب المختلفة وأدلتها الثرعية والتعليل الفقهي. وفيما يلي عرض الآراء في كل

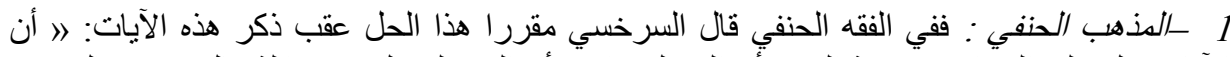

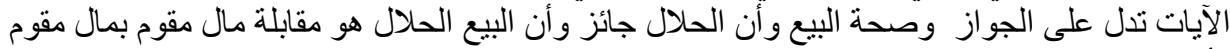

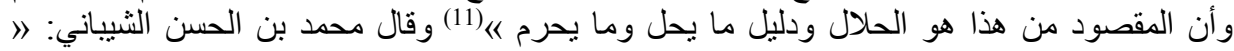

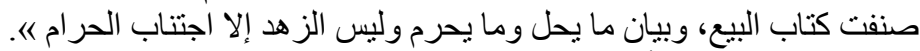

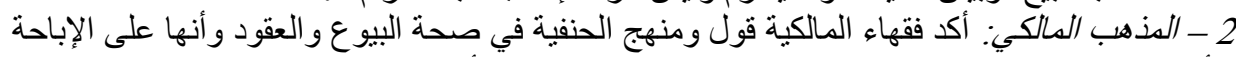

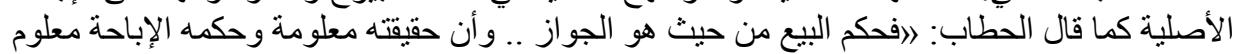

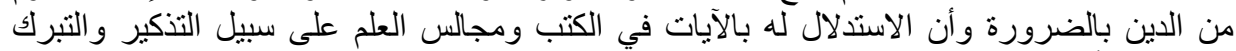

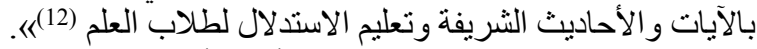

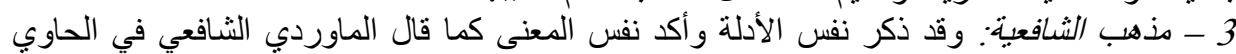

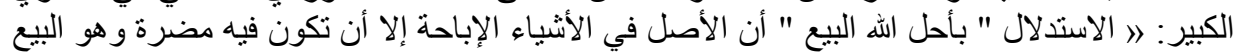

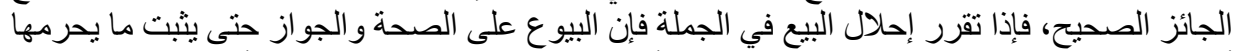

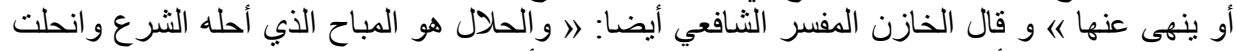

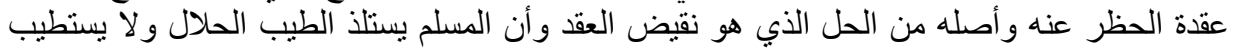

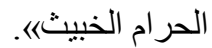

4 - مذهب الحنابلة: و عندهم نفس التأكيد الفقهي و المنهج في حل و إباحة المعاملات و العقود مع تفصيل

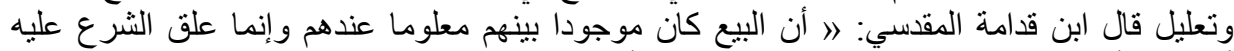

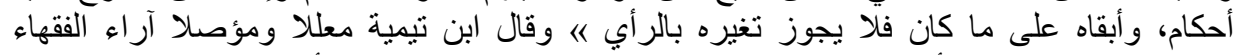

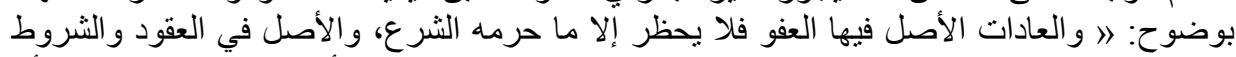

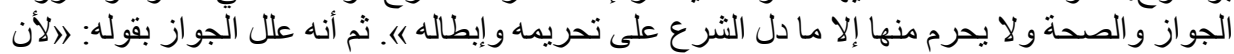

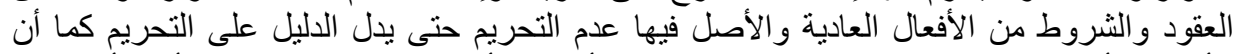

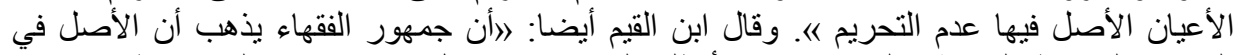

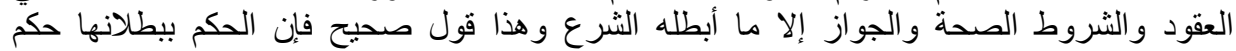

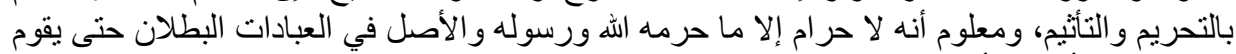

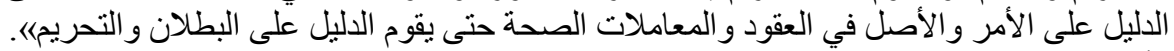

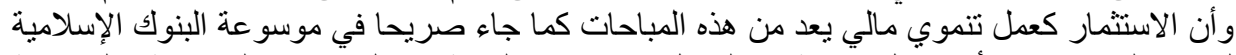

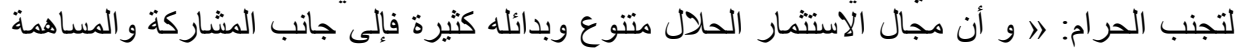

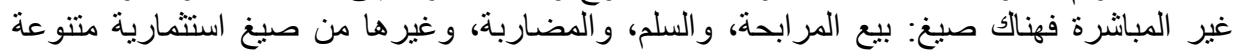

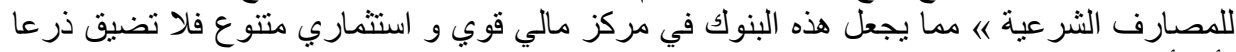

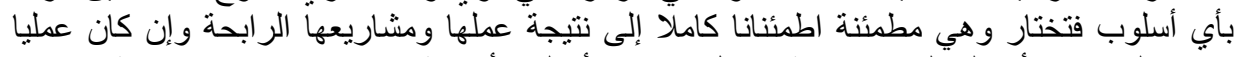

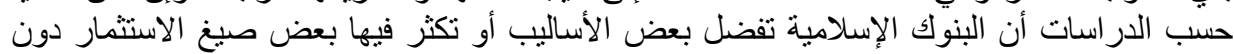

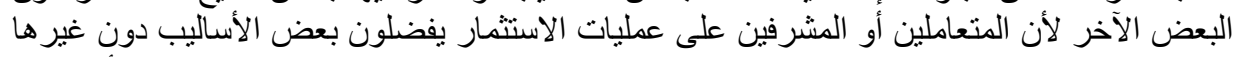

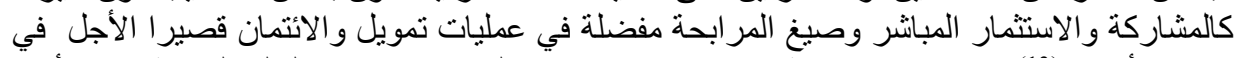

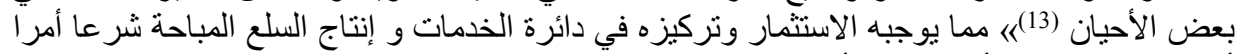

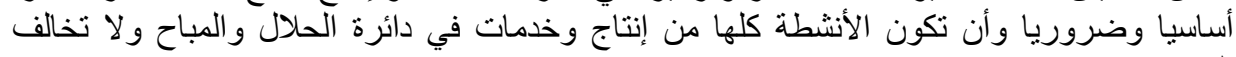

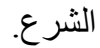
و هناك عدة أحاديث نبوية تجعل الإعمار والغرس صاحبه مأجور وتحث على الاستثمار و التتمية

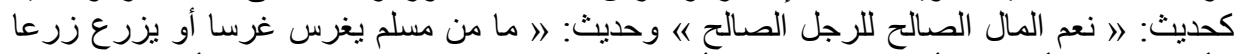

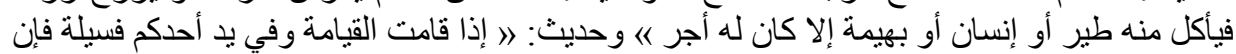

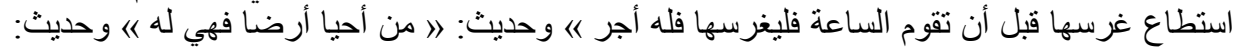




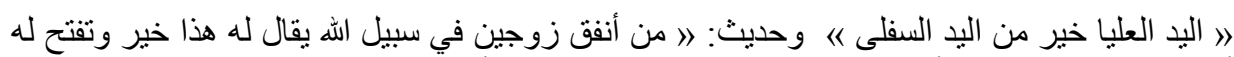

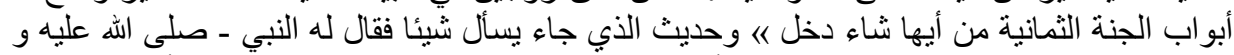

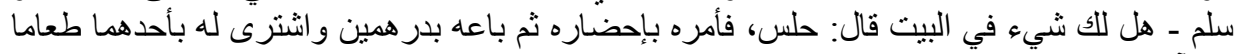

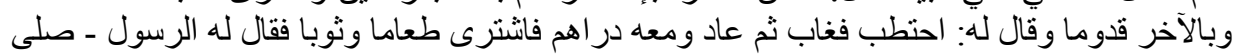

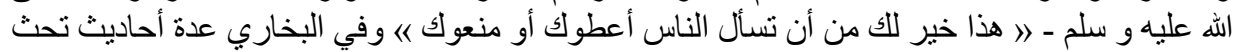

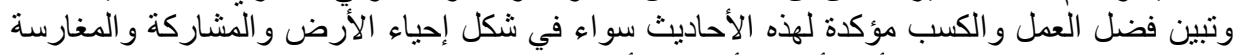

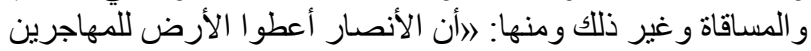

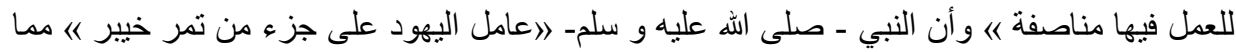

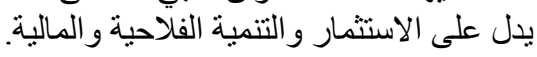

والخلاصة أن الصكوك شرعا تعد وسيلة استثمار وتمويل وتوفير السيولة النقدية عند التعامل في وتي

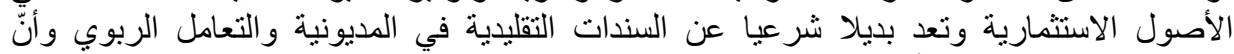

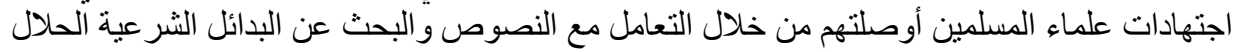

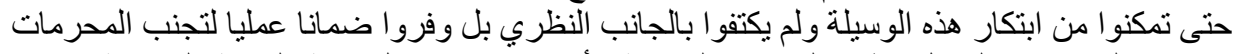

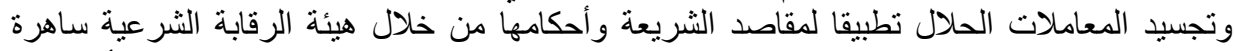

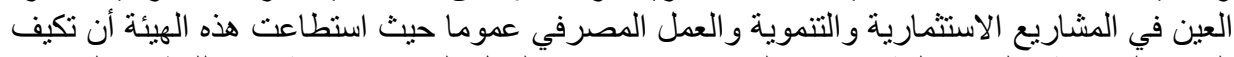

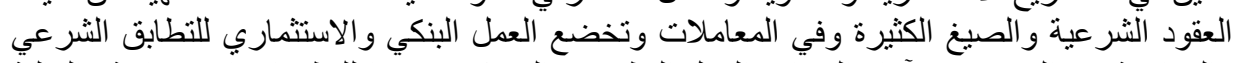

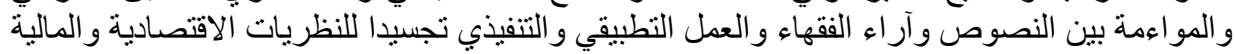

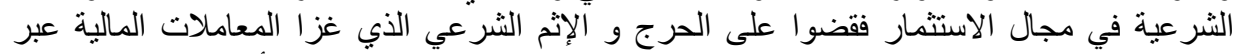

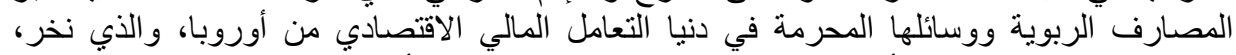

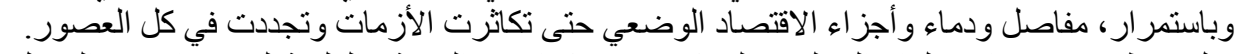

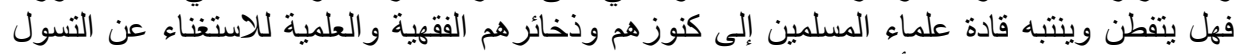
و الحلول المستوردة التي ملاتت بلاد المسلمين بالفساد و الكساد وجرّّت عليهم الويلات و السيطرة و الهيمنة

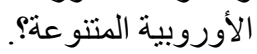

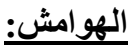

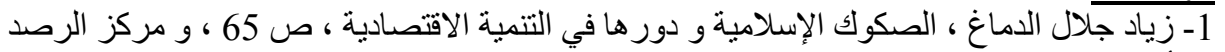

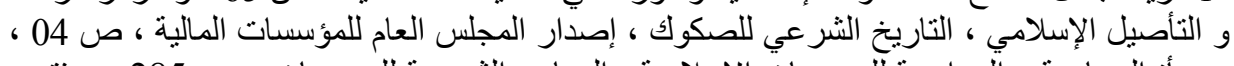

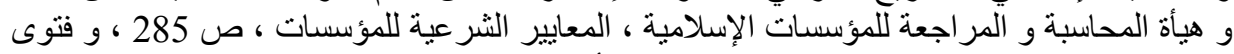

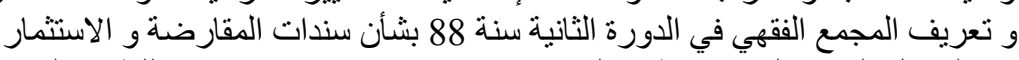

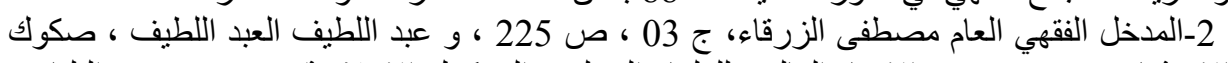

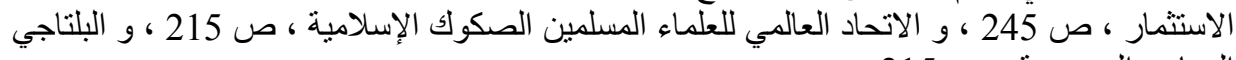

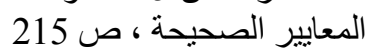
3-زياد جلال ، المرجع السابق ، ص صل 88 ، و و مجلة الفقه الإسلامي ، ج/03 ، ص 216 ، نادية أحمد

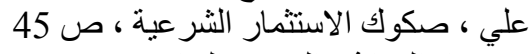

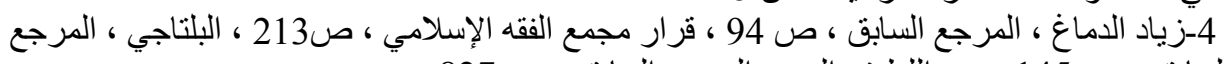

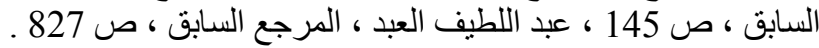
5-المعايير الثر عية، للمؤسسات المالية الإسلامية ، هيئة المحاسبة و المر اجعة للمؤسسات المالية

6-ميرة مشهور 》 الاستثمار في الاقتصاد الإسلامي 《) ص 35 - 40 - 40 .

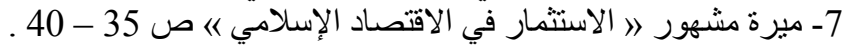

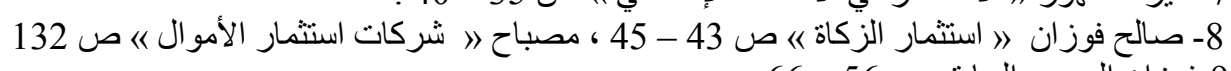
9-فوزان المرجع السابق صرزان 56 - 66 ـ 


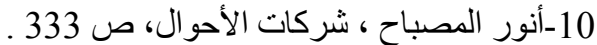

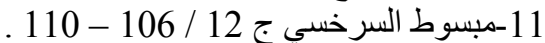

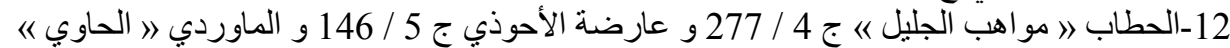

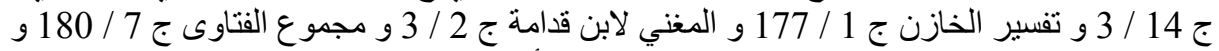

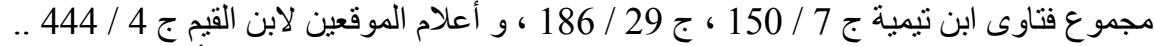

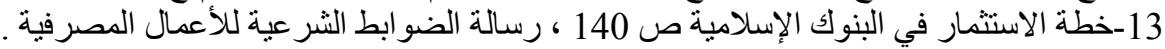

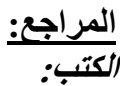

الدماغ زياد جلال. (2012). الصكوك الاستثمارية و دور ها في التتمية الاقتصادية. دار التقافة للنشر و التوزيع.عمّان. دوابه أشرف محمد.(2004). صناديق الاستثمار الإسلامية في البنوك الإسلامية. دار السلام للطباعة

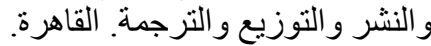

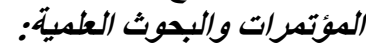

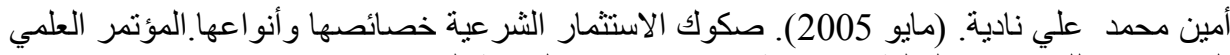

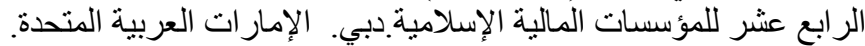

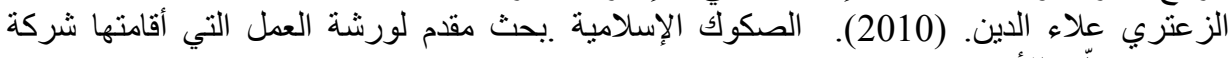

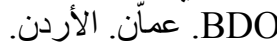

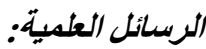

البلتاجي محمد. (1997). معايير تقويم أداء المصارف الإنهاءلامية. رسالة دكتور اه. كلية التجارة، جامعة الأز هر. الإن.

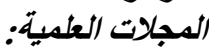

هيئة المحاسبة والمراهة المعة للمؤسسات المالية الإسلامية. (يونيو 2003). مجلد معايير المحاسبة

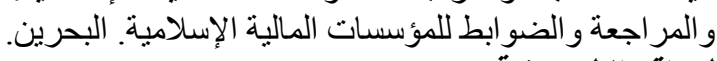

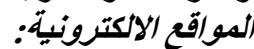

العنزي سعود بن ملوح. صكوك الاستثمار در اسة تأصيلية فقهية. رسالة دكتور اه. http://www.libback.uqu.edu.sa/hipres/Indu/indu11995.pdf 